\title{
Malignant Extra-Adrenal Paraganglioma
}

National Cancer Institute

\section{Source}

National Cancer Institute. Malignant Extra-Adrenal Paraganglioma. NCI Thesaurus. Code C4219.

An extra-adrenal parag ang lioma that metastasizes to regional or distant anatomic sites. Common sites of metastasis include the lymph nodes, lungs, bones, and liver. 